\title{
A Critical Look at the Concept of Addiction in DSM-5 and ICD-11
}

\author{
Joerg Petry \\ Federal Association of Gambling Addiction (NGO), Vice Chairman, Bielefeld, Germany
}

\section{Email address:}

joerg.petry@googlemail.com

\section{To cite this article:}

Joerg Petry. A Critical Look at the Concept of Addiction in DSM-5 and ICD-11. American Journal of Psychiatry and Neuroscience. Vol. 9, No. 1, 2021, pp. 7-14. doi: 10.11648/j.ajpn.20210901.12

Received: December 8, 2020; Accepted: December 16, 2020; Published: January 15, 2021

\begin{abstract}
The article begins by providing an overview of the conceptual roots of addiction as a disorder as described in DSM-5 and ICD-11. The underlying organ-pathological perspective is then criticized and an alternative social-science perspective is presented: The "dependence syndrome" defines addiction independently of the cultural, socio-demographic and situational context. States of inebriation are reduced to the effects of substances described in pharmacological terms. Diagnoses are based on only a few abstract criteria. The biography of the person affected is not taken into account; neither are the severity of the disorder (e.g. quantity and frequency of consumption or activity), sociodemographic characteristics or defense structure. The core concept of "impaired control" is a metaphor: The individual's hierarchically structured ability to control her addictive behavior is not clarified. Neurobiological models contain overgeneralizations and speculative connections between brain processes and addictive behavior. One aspect which remains unconsidered is that addiction is primarily social. Addiction is rooted in a continuing lack of social integration and requires a wide range of inebriation-specific incentives. Addictive behavior can be seen as a purposeful coping mechanism for excessive burdens. In order to overcome an addiction, the sufferer's autonomy needs to be strengthened in order to ensure the regeneration of physical health, individual competences and interpersonal relationships. This requires the cooperation of the relevant professional groups.
\end{abstract}

Keywords: Research Domain, "Dependence Syndrome”, State of Inebriation, Clinical Phenomenology, "Impaired Control", Condition Structure, Biomedicalization, Social Science Approach

\section{Introduction}

The revisions of the ICD after the Second World War were determined by WHO's changing concept of addiction [1]. One starting point was the definition of the term "drug addiction" by a commission composed primarily of pharmacologists in 1950: Drug addiction is a state of periodic or chronic intoxication, detrimental to the individual and society, produced by the repeated consumption of a drug (natural or synthetic). Its characteristics include: (1) an overpowering desire or need (compulsion) to continue taking the drug and to obtain it by any means; (2) a tendency to increase the dose; (3) a psychic (psychological) and sometimes physical dependence on the effects of the drug [2] p. 6. Elvin Morton Jellinek added the characteristic "loss of control" and assumed a yet unknown organic factor " $\mathrm{X}$ " as the cause [3]. The concept was further developed through the "dependence syndrome" of Griffith Edwards and Milton
Gross, in which the term "loss of control" was limited to "impaired control" [4]. Neurobiological research has now taken the place of factor X. With that, the disease concept of addiction - i.e. the medical model, which continues to be the determining factor in the development of this construct - was complete.

In accordance with this developmental history, alcoholism (acute and chronic) as well as "drug addiction" were initially classified (roughly) as independent categories in the sense of the disease concept in ICD-6 (1948). ICD-10 (1989) introduced the "dependence syndrome" as a foundational element. In ICD-11 (2019), this concept was applied to the behavioral addictions gambling disorder and pathological internet use (gaming disorder). In keeping with this, ICD-11 describes the paradigmatic "alcohol dependence syndrome" as follows: The characteristic feature is a strong internal drive to use alcohol, which is manifested by impaired ability to control use, increasing priority given to use over other 
activities and persistence of use despite harm or negative consequences. These experiences are often accompanied by a subjective sensation of urge or craving to use alcohol [5].

Despite the differences that have existed from the beginning, DSM-I (1952) adopted the disease concept from ICD-6 and currently defines alcohol use disorder as $a$ problematic pattern of alcohol use leading to clinically significant impairment or distress if a certain number of criteria are met [6] p. 490. These criteria also correspond to the characteristics of the "dependence syndrome" (among others, "impaired control," craving, tolerance, withdrawal). As in ICD-11, these characteristics are applied in DSM-5 to the behavioral addictions gambling disorder and internet gaming disorder.

Although the concept of "dependency syndrome" was subject to fundamental criticism early on and in subsequent years, the mentioned core characteristics "impaired control," etc. are now seen as completely natural descriptive characteristics of all forms of addictions, including behaviorrelated [7-9]. What has largely been forgotten, however, is that their defining characteristics still derive from Jellinek's organ-pathological concept.

For researchers, the question arises of whether the basic assumptions behind this concept of addiction (pharmacological view, neurobiological foundation) and its theoretical components (especially "impaired control" and craving) are theoretically and empirically justified. Furthermore, it has to be clarified whether the medical model can adequately represent the complex structure of an addiction's development.

For practitioners it is important to know which disorders can be classified as addictions (such as addictive overeating and sexual addiction) and must be treated accordingly, and which have to be regarded as independent mental disorders (such as pathological internet use), thus requiring other forms of treatment. Finally, it must be clarified how the disease concept affects the significance of pharmacotherapy, psychotherapy and social work within the addiction-care system.

\section{The Domain of Addictions}

The definition of disorders due to psychotropic substances and behavioral excesses in the sense of the "dependence syndrome" leads to an erroneous definition of "addiction" as the subject of research.

Two disorders described in ancient times and already characterized as addictions in the 16th century (obeseness) and 19th century (nymphomania or satyriasis) are excluded. Addictive overeating is completely omitted, as it is classified under nutritional disorders as obesity - which is as if alcoholism were listed under fatty liver. The description of "binge eating disorder" cannot sufficiently capture addictive overeating. A new clinical syndrome was created based on one symptom (eating attacks), which only occurs, more or less frequently, in a subgroup of addictive overeaters. In the tradition of German psychiatrist Emil Kraepelin, sexual addiction is not classified as an addiction, but continues to be classified as an impulse control disorder in ICD-11 [10]. The addiction-related definition of hypersexuality was not included in DSM-5 due to the alleged lack of empirical evidence [11].

Besides the long overdue inclusion of gambling addiction, a subgroup of pathological internet use (gaming disorder) is prematurely classified in ICD-11 as a disorder due to addictive behaviors, and as a non-substance-related disorder in DSM-5. Pathological chatting and streaming/surfing are not included. This is the equivalent of identifying a beerconsumption disorder while ignoring the addictive consumption of wine and spirits.

The reason for these contradictions is the abstractly defined addiction characteristics ("impaired control," priority of the addictive behavior, persistence despite negative consequences, and craving), which can lead to an arbitrary expansion of behavioral addictions, such as exercise dependence and workaholism [12, 13]. A theoretically derived and empirically based alternative would be Jim Orford's model of excessive appetites, which defines excessive drinking, drug-taking, gambling, eating and sexuality as core addictions [14].

\section{Characteristics of the "Dependence Syndrome"}

The characteristics of the "dependence syndrome" form the abstract theoretical basis of the construct "addiction." With regard to the term "craving," this means that cultural differences (binge drinking in Northern Europe vs. moderate drinking in Southern Europe), sociodemographic characteristics (gender, age, ethnicity, city vs. country) and the proximal conditions (initial mood, expectations, scene, social interaction) are not taken into account. And, of course, the psychotropic substances (alcohol, tobacco, opium, etc.) or inebriation-specific activities (gambling, eating, sex) that are chosen, especially their social regulation (legal vs. illegal), are significant for the shaping of craving, which thus comes in many different forms.

Operationalization by means of screening instruments also happens in a confirmatory manner, for example, if questions are only asked about the characteristic of "impaired control" in general, although the actual addictive behavior varies depending on the social and cultural context [15]. The anthropologist David Moore describes the alternation between "controlled" use of psychotropic substances in times of professional responsibility and uncontrolled consumption during periods of leisure: Thus, to speak of "impaired control" in this situation is misleading, because he declared the entire period to be one of 'time out' from control [16] p. 473.

The relevant questionnaires do not ask about concrete consumption behavior in light of the cultural and situational context. The findings lack ecological validity [17]. According to the so-called "heavy substance use over time" approach, the addictive characteristics of the "dependence syndrome" 
mentioned above are, moreover, dispensable. This is because both the neurobiological and other organic changes are predictable based on the extensiveness of the consumption alone, as are the addiction-related diseases and the increased mortality [18].

\section{Pharmacological Perspective}

In keeping with Emil Kraepelin's original taxonomy, addictions continue to be classified as chronic intoxication [10]. Substance-related addictions (alcohol use disorder, cannabis use disorder, opioid use disorder, etc.) are listed according to their pharmacologically described effects. Psychotropic substances, however, have a complex effect: Alcoholic beverages exhibit a biphasic effect (first stimulating, then inhibiting), tobacco smoking has a paradoxical effect (stimulating and calming) and opioid consumption is experienced as pleasant, unpleasant, neither or alternating [19].

The so-called animal model still plays a central role in pharmacological research. However, the Rat Park experiments conducted by Bruce Alexander in the 1970s still call its results into question [20]. Alexander was able to prove that rats that were not kept isolated in small laboratory cages, but in an animal-like environment with conspecifics, sufficient room to move and possibilities for play mostly preferred water instead of a morphine solution. The animals showed no signs of addiction-like development. An analysis of the animal studies on the self-administration of nicotine also points to obvious methodological deficiencies in pharmacological studies (no adequate control groups, insufficient standardization, food-deprived animals, statistical manipulations, etc.) [21].

The state of inebriation arises from the interaction of the psychotropic substance (drug) with the characteristics (predisposition, personality traits, mood, expectations, etc.) of the person (set) and the cultural-situational context (setting). This terminology was introduced as early as the 1960s by Timothy Leary with reference to well-controlled experiments with psilocybin and LSD [22]. Norman Zinberg later applied the three terms to the uncontrolled vs. controlled use of illegal substances (marijuana, psychedelics, opiates) [23]. The quality of inebriation consists of an "altered state of consciousness" that differs from the waking state in that it has a different relationship to external reality and can be measured as a dissociation-like state [24, 25]. The complexity of inebriation cannot be reduced to the substance effect: Although the consumption of a psychotropic substance triggers inebriation, it leaves the inebriation largely underdetermined. The dynamic interaction between social (everyday life), mental (perception, thoughts, feelings) and physical (activation-inhibition-balance) processes creates the state of inebriation.

In terms of lifestyle, the consumption of psychotropic substances not only depends on their effects. Inebriationspecific behavior serves above all to cope with everyday burdens [26]. Only in a few people does an addiction-specific lifestyle develop from this that permanently restricts their ability to take action. This applies both to the excessive use of psychotropic substances and to activities such as excessive gambling [27, 28].

The neurobiological processes of habit formation, which are held responsible for "impaired control," merely describe what happens physiologically when people frequently use a psychotropic substance or engage in inebriation-specific activities to excess. Beyond that, however, the impression is created that this stimulus-response association - mediated by subjectively experienced craving - can directly cause addictive behavior. A person's actions nevertheless remain oriented towards individual goals that serve to cope with everyday burdens: Although suffering from drug induced neurological changes that influence his behavior, the addicted person nonetheless engages in behaviors that are purposeful [26] p. 212. Nor is it explained for what reasons a person decides to continue or discontinue their addictive behavior [29, 30].

\section{5. "Impaired Control"}

ICD-11 classifies two disorders - gambling disorder and a subgroup of pathological internet use (gaming disorder) - as addictive behavioral patterns. The three identical characteristics of both disorders are the "impaired control" of gambling or gaming, the predominance of this behavioral excess over other areas of life, and the continuation of or increase in problematic behavior despite negative consequences. This corresponds to selected characteristics of the "dependence syndrome." The term "loss of control" is attenuated to the term "impaired control." It must be remembered that the term has its origins in religious pamphlets of the 16th century. Some theologians understood the loss of control as God's punishment for sinful drinking. At the beginning of the 19th century, the term was introduced into medicine by the physician Benjamin Rush [31]. The autodidact Jellinek took it up and placed it at the center of his organically based concept of alcoholism [3]. This led to a metaphorical exaggeration that continues to this day - which is surprising, since it is a pseudo-scientific concept that is not anchored in any biological or psychological theory.

Above all, it is not explained which control mechanisms are involved. The personality theory of Julius Kuhl contains a hierarchical model of self-regulation processes [32]. Addiction-related habit formation only refers to the level of cognitive and motor operations (learning) and, in part, to affect and incentive motivation. But addictive behavior and its overcoming are also based on changes at the levels of temperament (arousal and activation), basic motives, cognitions, consciousness and will. Between the bodyadjacent and higher mental levels lie the mediating control forms of progression (here: suppression of habits through higher-level regulation) and regression (here: blocking the suppressive regulation of habits). Treatment and abstinence influence changes in all of these self-regulation functions [33]. 
These complex processes cannot be interpreted as an impairment or even "loss of control": Craving resulting from strong habit formation is not "irresistible" - quasi detached from the control abilities of the personality - but is subject to a hierarchical regulation process. Addicts can control their addictive behavior depending on the context and can also stop it permanently if it contradicts their system of values or has lost its meaning in their everyday life $[15,16,29]$. They often do this without therapeutic help [34]. This intentional control and the complete cessation of symptomatic behavior are the very special characteristics of this disorder.

\section{Psychopathology of Gambling Addiction vs. Pathological Internet Use}

According to the German psychiatrist and philosopher Karl Jaspers, psychiatric phenomenology is tasked with describing the real, experienced conditions of its patients, looking at similarities and differences, and delimiting them as exactly as possible [35]. In DSM-5 and ICD-11, in contrast, a process of abstraction takes place in which complex clinical pictures are broken down into several separate classes on the basis of selected characteristics. In the case of an addiction, its associated depressive symptoms are classified separately as depressive disorders. Even if a person may have more than one disorder at the same time, mental disorders are complex phenomena made up of different components. At the core of every addiction are feelings of guilt and shame, which drive a destructive overall process [36]. These depressive elements cannot be separated from the addiction development. They form a vicious circle, which explains the high suicide rate among those with addictions.

At the same time, individual signs of the disorder are highlighted and a more or less meaningful threshold value is defined. The selection of characteristics is based on the disease model of addiction, which according to Karl Jaspers is a "somatic prejudice" [35] p. 15.

If these abstract features serve as criteria for individual diagnostics, the clinical view of the individual case is narrowed down. In doing so, the individual's biography, history of problems, existing feelings of guilt and shame, defense mechanisms, attempts to solve problems, supportive social network and everyday situation are not taken into account.

In addition, the screening instruments used merely record the subjective statements of those affected. The objective clinical measurement is missing: The mild, rapidly rebounding symptoms that gambling addicts experience when they stop gambling are interpreted as withdrawal symptoms and are thus considered typical of addiction [37]. This is done without the necessary physical examination (tachycardia, hypertension, etc.).

This is illustrated by the example of gambling disorder and a subgroup of pathological internet use (here: gaming disorder) - two completely different clinical pictures. ICD-11 classifies the two disorders as belonging together on the basis of three vaguely defined characteristics ("impaired control," increased priority given to gambling/gaming over other activities, continuation of gambling/gaming despite negative consequences). DSM-5 also includes other characteristics such as tolerance and withdrawal symptoms. According to Karl Jaspers, psychogenic diseases (meaning neuroses, personality disorders and addictions) can only be typologically captured, whereby particularities of the personality, typical states of experience and development processes are used [35].

In this sense, the two disorders mentioned can be clinically typologized as addicted (gambling addiction) and nonaddicted (pathological internet use). As becomes clear even at first glance: There are the physically restless, curious, assertive and mostly male gambling addicts, and there are the restrained, withdrawn, inhibited and likewise predominantly male internet users.

The typical gambling addict hides his diminished selfesteem and fear of relationships behind a facade of superiority and distant aloofness. This expresses itself in social arrogance and a demarcating withdrawal from the bourgeois world. What counts for him is the state of inebriation that elevates him above everyday life. Due to his social adaptability and professional skills, he can initially compensate for financial losses. Chasing, i.e. the tendency to increase betting in an effort to recoup prior losses, leads to a self-damaging and alienating downward spiral of lies, suicidal tendencies and crime - typical characteristics of an addiction career. The basis for symptomatic treatment is the principle of total lifelong abstinence. The therapeutic relationship is initially characterized by suspicious distance. It is at risk as soon as demands are made to cope with the addiction-related consequences (debt, responsibility in relationships).

The typical pathological internet user (here: excessive gamer) does not experience a dissociative-like state of inebriation. Despite intensive immersion in the virtual world, gaming behavior is characterized by an alert, interruptible working mode. Due to his low level of goal pursuit and reduced ability to sustainably master everyday problems (low conscientiousness as a Big Five personality trait), the gamer withdraws into virtual reality. Only there can he experience success in the community of fellow players - a retreat into the world of childish fantasies of omnipotence. His social behavior is characterized by depressive insecurity and fear of contact. Pathological gaming increases the tendency to remain without a partner or employment. Social anxiety and retreating from the world are mutually dependent on each other - the typical image of an attachment disorder. The "traffic light model" serves as the basis for symptomatic treatment (prohibited online activities are marked red, dangerous yellow and desirable green) according to which the use of the internet is limited to the applications necessary for school and professional life and everyday needs. Attention accorded in the therapeutic relationship is gratefully received. Problems arise from the overestimation 
of competences related to everyday life and from unrealistic professional expectations.

This typology was confirmed by a comparative clinical study carried out at two German rehabilitation clinics: Pathological internet users (of the gaming, chatting and surfing/streaming type) could be distinguished as an independent group from substance-related (alcohol) and nonsubstance-related (gambling) addictions and psychosomatically ill persons. The subjects' comparatively reduced conscientiousness was the most important distinguishing characteristic [38].

\section{Conditional Structure}

In the prevailing medical model, the horse is put behind the cart: The supposedly addiction-specific brain processes are offered as primary explanatory concepts and are made the basis for pharmacological treatment strategies. Colorful MRI images have become part of the everyday understanding of addiction. Neurobiological research defines the field. Accordingly, the term "biopsychosocial model" is used. A socio-psycho-biological understanding would be more correct.

A thought experiment will explain this: Robinson Crusoe is stranded - we leave his biographical experiences in the civilized world unconsidered - on a desert island where he first has to find food. Fortunately, he discovers plenty of vegetation. It is inevitable that he consumes a plant or fruit that leads to a first state of inebriation. He feels very comfortable with this, so he wants to repeat the experience. A craving develops that leads to regular consumption. His body adapts so that he needs a larger dose to achieve the same effect. Sometimes Robinson is so inebriated that he barely survives dangerous situations in the wild. He interrupts his consumption, but cannot bear the negative body reactions and feelings - and resumes his inebriation-specific behavior. His consumption gradually gets out of control and the search for psychotropic substances now determines his daily routine. Since he no longer eats enough, he becomes increasingly emaciated. He no longer cares about maintaining his wooden hut, which leaves him at the mercy of the changing climate. He falls ill more and more frequently. Fortunately, a ship sails to the island and the ship's doctor, who is familiar with seafarers' addictions, takes him in for treatment. Let's end the tale for now on this positive note.

But - what is wrong with this story?

It is hard to imagine Robinson being in a position to merely "explore" the psychotropic properties of various substances found in nature. He probably would have met an early death by eating a toxic mushroom or berry that is difficult to dose.

The handling of psychotropic substances requires a social community that has developed techniques for preparing the substances so they can be agreeably consumed. This handling also requires community rituals that restrict consumption, i.e. a culture of inebriation [39]. It is also difficult to imagine Robinson roaming his island as a lonely drinker or pothead.
Addictions never occur only in single individuals. In order to overcome the often-unpleasant side effects experienced during initial use (think of your first drinking binge), some form of social protection is needed. Social instruction is also required for perceiving the substance's actual effect (e.g. being high) [40]. The lonely island inhabitant would probably not have gotten beyond his first unpleasant attempts at consumption and would have turned to less problematic food.

The first step is always social. People are social beings who actively appropriate their environment. But it is a long way from regular consumption to addiction. This requires special social circumstances. In simplified terms, inebriationspecific activities serve to cope with everyday burdens. The focus is on the self-regulation of associated unpleasant feelings. Particularly affected are people who have a predisposition to react helplessly to problems. This diathesisstress model determines the interactions between the social environment and the individual's mental and physical vulnerability. This means, first of all, that addiction can only develop if social structures that are associated with particular problems remain in place. Bruce Alexander refers to the historical variations and the stratum-specific differences that lead to the spread of addictions in society. According to his theory, individual and collective addictive developments are rooted in a permanent lack of social integration (dislocation) and experiences of alienation [41]. A further necessary social condition for addictions is a - more or less - prevailing oversupply. Gerda Reith describes this connection between the structure of consumer capitalism and the collective excesses of drugs, food and gambling [42]. Economists Anne Case and Angus Deaton analyze the socio-economic roots of the declining life expectancy of the white underclass in the late-capitalistic United States. They call fatalities resulting from opioid overdoses (read: OxyContin), suicides and alcohol-related illnesses "deaths of despair" [43].

Our lonely islander was surely only able to use psychotropic substances sporadically. He lived a life close to nature and was not confronted with an oversupply of inebriation-specific incentives (alcohol, gambling, food). Finally, there were no conspecifics who would have encouraged the castaway to use such substances or engage in inebriation-specific activities. Such behavior would certainly not have been characteristic of becoming an adult or of social affiliation.

\section{Biomedicalization}

Within the medical model, the focus is on the organic brain processes, although the assumptions and empirical findings developed for this purpose are still very preliminary. One example is the much-cited incentive-sensitization theory of addiction: It begins with experimental findings, according to which a restricted dopamine neurotransmission can reduce the pleasurable drug effect ("liking") without leading to a reduction of craving ("wanting"). With reference to imaging techniques, it is assumed that the activity in specific brain 
regions is decisive. Frequent drug use increases the reactivity of the mesolimbic system and thus increases cue-reactivity to drug-related stimuli. The unconsciously occurring addictive behavior becomes compulsive [44].

The incentive-sensitization theory of addiction is merely a hypothesis that refers only to craving as a partial aspect of addiction. Presenting this as an addiction theory is an overgeneralization. An addiction theory must be based on a model of dynamic processes of motivation and self-regulation. This approach was further elaborated by Robert West and Jamie Brown. According to their model, automated habits, impulses (and their inhibition), feelings, drives, motives, evaluations and plans determine addictive behavior [45]. In addition, cultural-historical and socio-economic conditions must be taken into account.

Regarding the hasty interpretations of the neurobiological findings, it can be said that we do not know what it means when specific areas in the brain are particularly active, or what the meaning of the processes is in less active areas or how the two are connected. The neurobiological processes in the brain represent necessary conditions that enable, but do not determine, addictive developments. The brain is a mediating organ for the physical, mental and social relationship between the whole person and the world [46]. The reduction of addictive behavior to specific brain processes not only hides the addictive career of the person concerned and the typical processes of shame, but also the existential abyss and the associated suicide risk.

How is it possible that such a mainstream understanding could develop from the one-dimensional concept of disease? In sociology this is called "biomedicalization" [47]. This concept describes the social, economic, legal and political processes that lead to the development of such a movement. This includes the shift of financial resources to institutions that produce an authority-based knowledge base (here: neurobiology). New groups of patients are being defined (think of today's new addictions), for which novel forms of treatment (pharmacotherapy) are being promoted. Within the members of a research area, a near consensus develops, which finds expression in scientific journals and congresses [21]. Working groups of selected experts, who often have close ties to the pharmaceutical industry, develop national guidelines for treatment and determine the codification of the international classification systems (currently DSM-5 and ICD-11) [48]. The results are disseminated in the media and taken up by politicians. One example is the hype surrounding so-called behavioral addictions and, especially, internet use disorder [49, 50]. The system of politics, business lobby, judiciary, media, externally funded research, professional associations and treatment institutions is thus complete.

In the meantime, a biomedical bubble has formed on the basis of a rapidly growing pharmaceutical and biotechnological industry [51]. One example is the administration of the anti-craving substance nalmefene, which in a controlled study resulted in the amount of pure alcohol consumed per day being reduced by 11 grams after six months compared to the control group [52]. This corresponds to roughly a quarter liter of beer, i.e. a small fraction of the average daily consumed quantity of several liters. So far, pharmacotherapy is not a cost-effective intervention compared to established psychotherapy [53]. There is instead the danger that psychosocial interventions which focus on the lifestyle of the individuals in question will increasingly lose ground due to these developmental trends.

\section{The Social-science Perspective}

An alternative approach sees addictive behavior patterns as being based on the lifestyle of specific individuals [54]. Accordingly, addictive and "controlled" behavior patterns vary due to current life situations [15]. Addictive behavior can be seen as a coping strategy within the framework of an addictionspecific lifestyle [27]. The form and extent of problematic and addictive behavior patterns result from the need to cope with everyday stresses and strains by adapting to or deviating from societal norms. The range extends from socially accepted drinking to the consumption of illegalized psychotropic substances within a community of addicts $[15,55]$.

Addictive behavior is experienced as justified, goaloriented, purposeful action, which appears functional despite all its disadvantages for other areas of life. The social contradictions and the resulting limited possibilities for action, the specific emptiness of everyday life and the social isolation of those affected determine the resulting addictionspecific lifestyle [27, 55].

Overcoming an addiction results from the conflict between the attachment to the addiction-specific experience and the associated restraints, be they physical (secondary diseases), mental (reduced self-esteem) or external (social sanctions). This leads to a re-evaluation of one's life and values [14]. Recovery often takes the form of a self-change process [31]. However, treatment may be necessary in advanced states of addiction.

\section{Conclusion}

Autonomy is the linchpin for overcoming addiction - not the treatment of a way of life defined as a disease. Addicts are given opportunities for action and freedom so that they can build a "new" life in a self-determined way: We need to continue to create more nuanced conceptions of addiction and recovery along with conceptions of choice, free will, and responsibility [56] p. 43. This requires that addicts overcome the many forms of self-deception that exist $[56,57]$.

This also requires integrated cooperation between the professions involved and a clear division of labor: Medical treatment should be primarily directed at restoring physical health (withdrawal and treatment of secondary diseases) and, if necessary, at the accompanying mental illnesses; it can also include pharmacotherapy. Psychotherapy should aim to promote self-responsibility as a way of strengthening autonomy and self-determination on the part of the individual receiving care [58]. Social-work interventions should serve to 
restore interpersonal relationships and social integration within the recovery process [59].

\section{Declarations}

The author declares that he has no competing interests.

\section{References}

[1] Bjerge B, Houborg, E. et al. WHO expert committees and key concepts for drugs, alcohol, and tobacco 1949-2013. In M. Hollman \& V. Berridge et al., eds. Concepts of addictive substances and behaviors across time and place. Oxford (UK): Oxford University Press; 2016: 57-86.

[2] World Health Organization (1950). Expert committee on drugs liable to produce addiction. Technical Report Series No. 21. Geneva: Palais des Nations.

[3] Jellinek E. M. (1960). The disease concept of alcoholism. New Brunswick, N. J.: Hillhouse Press.

[4] Edwards G, Gross M. M. Alcohol dependence: Provisional description of a clinical syndrome. British Medical Journal 1976; 1 : 1058-1061.

[5] ICD-11 for mortality and morbidity statistics (version 04/2019). https://icd.who.int/browse11/1m/en\#/http\%3a\%2f\%2fid.who.int\%2ficd\%2fentity\%2f1580466198.

[6] American Psychiatric Association (2013). Diagnostic and Statistical Manual of Mental Disorders. DSM-5. Washington, D. C.: American Psychiatric Publishing.

[7] Shaw, S. A critique of the concept of the alcohol dependence syndrome. British Journal of Addiction; 1979: 74, 339-348.

[8] Peele, S. (1998). The meaning of addiction: An unconventional view. 2nd ed. San Francisco, Cal.: Jossey-Bass.

[9] Fraser, S., Moore, D. \& Keane, H. (2014). Habits: Remaking addiction. Basingstoke (UK): Palgrave Macmillan.

[10] Kreapelin, E. (2015). Psychiatrie - ein Lehrbuch für Studierende und Ärzte, Zweiter Band. Norderstedt: Verlag der Wissenschaften (originally 1899).

[11] Kafka, M. P. Hypersexual disorder: A proposed diagnosis for DSM-V, Archives of Sexual Behavior; 2020: 39 (2), 377-400.

[12] Veale, D. M. W. Exercise dependence. British Journal of Addiction; 1987: 82; 735-740.

[13] Quinones, C. \& Griffiths, M. D. Addiction to Work: A critical review of the workaholism construct and recommendations for assessment. Journal of Psychosocial Nursing; 2015: 53 (10), 48-59.

[14] Orford J. (2001). Excessive appetites: A psychological view of addictions. 2nd ed. Chichester (UK): John Wiley.

[15] Sudhinaraset, M., Wigglesworth, C, Takeuchi, D. T. Social and cultural contexts of alcohol use: Influences in a socialecological framework. Alcohol Research 2016; 38: 35-45.

[16] Moore D. Deconstructing "dependence": An ethnographic critique of an influential concept. Contemporary Drug Problems 1992; 19: 459-490.
[17] Bronfenbrenner, U. (1979). The ecology of human development: Experiments by nature and design. Cambridge, MA: Harvard University Press.

[18] Rehm J, Marmet S et al. Defining substance use disorders: Do we really need more than heavy use? Alcohol and Alcoholism 2013; 48: 633-640.

[19] Angst MS, Laura C et al. Aversive and reinforcing opioid effects: A pharmacogenetic twin study. Anesthesiology 2012; 117: $22-37$

[20] Alexander BK. (2011). The globalization of addiction: A study in poverty of the spirit. 2nd ed. Oxford (UK): Oxford University Press.

[21] Frenk H, Dar R. (2000). A critique of nicotine addiction. New York: Springer Science.

[22] Leary T. The religious experience: Its production and interpretation. Psychedelic Review 1964; 1: 324-346.

[23] Zinberg N. E. (1984). Drug, set, and setting: The basis for controlled intoxicant use. New Haven, CT: Yale University Press.

[24] Ludwig A. M. Altered states of consciousness. Archives of General Psychiatry 1966; 15: 225-234.

[25] Jacobs D. F. Evidence for a common dissociative-like reaction among addicts. Journal of Gambling Studies 1988; 4: 27-37.

[26] Graham, M. \& Bitten, C. (2015). Counseling intentional addiction recovery grounded in relationships and social meaning, in R. A. Young, J. F. Domene \& L. Valach, eds. Counseling and action. New York: Springer; 2015: 211-222.

[27] Graham, M. D., Young, R. A., Valach, L. \& Wood, R. A. Addiction as a complex social process: An action theoretical perspective. Addiction Research \& Theory 2008; 16: 121-133.

[28] Walters G. D. The gambling lifestyle I: Theory. Journal of Gambling Studies 1994; 10: 159-182.

[29] Russell C, Davies J. B. Empirical, logical and philosophical arguments against cigarette smoking as a pharmacologically compelled act. Current Psychology 2009; 28 (3): 147-168.

[30] Baumeister R. F. Addiction, cigarette smoking and voluntary control of action: Do cigarette smokers lose their free will. Addictive Behaviors Reports 2017; 5: 67-84.

[31] Levine, H. G. The discovery of addiction: Changing conceptions of habitual drunkenness in America. Journal of Studies on Alcohol 1978; 39 (1): 143-174.

[32] Kazén, M. \& Quirin, M. The integration of motivation and volition in personality systems interaction (PSI) theory, in N. Baumann, M. Kazén, M. Quirin \& S. L. Koole, eds. Why people do the things they do. Boston, MA: Hogrefe; 2015: 1530 .

[33] Bętkowska-Korpala, B \&Olszewska, K. Self-regulation in the process of recovery from alcohol addiction according to Julius Kuhl's theory. Archives of Psychiatry and Psychotherapy 2016; 4: 63-74.

[34] Klingemann, H. \& Sobell, L. C. (2007). Promoting selfchange from addictive behaviors: Practical implications for policy, prevention and treatment. Boston, MA: Springer. 
[35] Jaspers, K. (1948). Allgemeine Psychopathologie. Fifth ed. Berlin: Springer. (originally 1913).

[36] Wiechelt, S. A. The specter of shame on substance misuse. Substance Use \& Misuse 2007, 42: 399-409.

[37] Wray, I. \& Dickerson, M. G. Cessation of high frequency gambling and "withdrawal" symptoms. British Journal of Addiction 1981; 76: 401-404.

[38] Schuhler, P, Sobottka, B. et al. (2013). Pathologischer PC/Internet-Gebrauch bei Patient/Innen der stationären psychosomatischen und Suchtrehabilitation. Lengerich: Pabst.

[39] Siegel, R. K. (1989). Intoxication: The universal drive for mind-altering substances. Rochester, VT: Park Street Press.

[40] Becker, H. S. Becoming a marihuana user, in H. S. Becker, Outsiders: Studies in the sociology of deviance. New York, NY: The Free Press; 1963: 41-58.

[41] Alexander, B. K. Addiction: A structural problem of modern global society, in H. Pickard \& S. H. Ahmed, eds. The Routledge handbook of philosophy and science of addiction. London (UK): Routledge; 2019: 501-510.

[42] Reith, G. (2019). Addictive consumption: Capitalism, modernity and excess. London: Routledge.

[43] Case, A. \& Deaton (2020). A. Deaths of despair and the future of capitalism. Princeton, NJ: Princeton University Press.

[44] Berridge, K. C. \& Robinson, T. E. Liking, wanting and the incentive-sensitization theory of addiction. American Psychologist 2016; 71 (8): 670-679.

[45] West R \& Brown J. (2013). Theory of addiction. 2nd ed. Chichester (UK): John Wiley.

[46] Northoff; G. (2018) The spontaneous brain: From the mindbody to the world-brain problem. Cambridge, MA: The MIT Press.

[47] Campbell NC. Medicalization and biomedicalization: Does the diseasing of addiction fit the frame? In J. Netherland, Critical perspectives on addiction. Bingley (UK): Emerald; 2012: 3-25.

[48] Frances A. (2013). Saving normal: An insider's revolt against out-of-control psychiatric diagnosis, DSM-5, Big Pharma, and the medicalization of ordinary life. New York, NY: William Morrow.

[49] Billieux, J., Schimmenti, A., Khazaal, Y., Maurge, P. \& Heeren, A. Are we overpathologizing everyday life? A tenable blueprint for behavioral addiction research. Journal of Behavioral Additions 2015; 4 (3): 119-123.

[50] Kardefelt-Winther, D. Conceptualizing internet use disorders: Addiction or coping process? Psychiatry and Clinical Neurosciences 2017; 71: 459-466.

[51] The Lancet (Editorial). UK life science research: Time to bust the biomedical bubble 2018; 392: 187.

[52] Mann, K, Bradström, A., Torup, C., Gual, A. \& van den Brink, W. Extending the treatment options in alcohol dependence: A randomized controlled study of as-needed nalmefene. Biological Psychology 2013; 73 (8): 706-713.

[53] Palpacuer, C., Duprez, R., Huneau, A., Locher, C., Boussageon, R. Pharmacologically controlled drinking in the treatment of alcohol dependence or alcohol use disorders: a systematic review with direct network meta-analysis on nalmefene, naltrexone, acamprosate, baciofen and topiramate. Addiction 2018; 113: 220-237.

[54] Kollind T., Thom B. \& Hunt G. (2017). The SAGE handbook of drug and alcohol studies: Social science approaches. London (UK): SAGE.

[55] Becker, H. S. Marihuana use and social control, in H. S. Becker, Outsiders: Studies in the sociology of deviance. New York, NY: The Free Press; 1963: 59-78.

[56] O'Connor, P. (2016). Life on the rocks: Finding meaning in addiction and recovery. Las Vegas, NV: Central Rcovery Press.

[57] Peele S. (2013). Recover! Boston, MA: Da Capo.

[58] Potter, N. N. Grounding for understanding self-injury as addiction or (bad) habit, in J. Poland \& G. Graham, eds. Addiction and responsibility. Cambridge, MA: The MIT Press; 2011: $200-224$.

[59] White, W. L. Addiction recovery: Its definition and conceptual boundaries. Journal of Substance Abuse Treatment 2007; 33: 229-241. 